\title{
PARÂMETROS GENÉTICOS EM MAXIXE SEM ESPÍCULOS.
}

\author{
Waldelice Oliveira de PAIVA ${ }^{1}$
}

RESUMO - Dezenove progênies de meios irmãos de maxixe (Cucumis anguria L.) com epiderme sem espículos (frutos lisos) foram avaliadas e estimados os parâmetros genéticos em seis características agronômicas. Altos valores de herdabilidade, ao nível de médias, foram achados para número de frutos e produção. Estimou-se que a seleção de $20 \%$ das melhores progênies resultará em aumentos de $8,09 \%$ e $20,94 \%$ respectivamente, na produção e no número de frutos.

Palavras-chave: Maxixe (Cucumis anguria L.), herdabilidade, ganho esperado, produção de frutos. Genetic Parameters in Spineless Gerkin (Cucumis anguria).

ABSTRACT - Nineteen half-sib of spineless gerkin progenies were evaluated for six agronomic characters and estimated the genetic parameters. High heritability values at means level were found for fruit number and yield. It was estimated that the selection of the $20 \%$ superior progenies will result in increases of $8,09 \%$ and $20,94 \%$ on yield and number fruit, respectively.

Key-words: gerkin (Cucumis anguria L.), heritability, expected genetic gain, yield.

\section{INTRODUÇÃO}

Na Amazônia, o maxixe (Cucumis anguria L.) é raramente submetido ao cultivo racional e na maioria das vezes é coletado nas populações subespontâneas em roçados ou em plantios de subsistência (PAIVA, 1984). O seu uso, porém, é amplamente difundido e ocupa posição de evidência entre as demais hortaliças junto à população.

Nos mercados e feiras livres, encontra-se grande variação de frutos, desde os com a epiderme cuja ausência de espículos é completa até aqueles totalmente espiculosos. A espiculosidade é um caráter conferido por dois pares de genes que nas formas duplamente dominante ou recessiva resulta em frutos com alta ou nenhuma espiculosidade, enquanto que os heterozigotos manifestam graús de espiculosidade intermediária (YOKOYAMA, 1987; KOCH \& COSTA, 1991).
Populações que se apresentem uniformes para o caráter ausêncịa de espículos são interessantes porque podem ser direcionadas para melhorar os caracteres que preencham os requisitos de cultivo comercial. O sucesso de tal empreitada, entretanto, depende do maior conhecimento da espécie e do gráu de variabilidade existente nas populações.

MIKI (1986) verificou que uma cultivar com epiderme sem espículos apresentava maior valor na relação entre o número de flores femininas e o número de flores masculinas, os frutos mostravam-se com dimensões ligeiramente superiores, enquanto que as plantas floresciam mais tardiamente que outra cultivar com frutos cuja epiderme era espiculosa.

De acordo com YOKOYAMA (1987), a base genética do germoplasma nacional de maxixe é bastante restrita e

Instituto Nacional de Pesquisas da Amazônia - INPA - Caixa Postal 478, 69.011-970 - Manaus - AM, Brasil. 
sugere que para ampliá-la sejam usados os parentais selvagens do mesmo gênero. A variabilidade em progênies de maxixe com frutos com epiderme sem espículos já foi avaliada anteriormente por PAIVA (1984). Os resultados indicaram que existe variabilidade suficiente para ser explorada no melhoramento de alguns caracteres de interesse agronômico. As herdabilidades para o número e produção de frutos, por exemplo, se mostraram elevadas.

Este trabalho foi conduzido com o objetivo de estimar alguns parâmetros genéticos em seis caracteres em dezenove progênies de maxixe da qual as plantas produzem frutos com a epiderme sem espículos e superfície costelada.

\section{MATERIAL E MÉTODOS}

As dezenove progênies de meios irmãos foram obtidas de uma população segregante composta de um pool de gerações de vários cruzamentos de maxixe (PAIVA, 1984). Essas progênies caracterizavam-se por produzirem frutos grandes, com a epiderme sem espículos e superfície costelada ou com formações longitudinais semelhantes a asas ou aletas.

As progênies foram avaliadas em um experimento instalado na Estação Experimental de Hortaliças do INPA, em Manaus-AM, na qual o solo mostra textura arenosa e com baixa fertilidade. A adubação constou de um litro de esterco de galinha por cova, sendo aplicados dez gramas de uréia por cova, em cobertura, no início do florescimento.

O delineamento experimental usado foi o de blocos ao acaso, com nove plantas em parcelas de $45 \mathrm{~m}^{2}$. Avaliaram-se as seguintes características: comprimento longitudinal do fruto (CF), em centímetros; diâmetro do fruto (DF), em centímetros; espessura da. polpa (ESP), em milímetros; peso médio de frutos (PMF), em gramas; número de frutos (NF) por planta e produção (PROD), em gramas de frutos por planta.

As análises de variâncias seguiram metodologia de PIMENTEL GOMES (1978) e as estimativas dos parâmetros genéticos foram obtidas de acordo com VENKOVSKY \& BARRIGA (1992). Para o cálculo do índice K, utilizou-se de metodologia e tabela citada por VENKOVSKY \& BARRIGA (1992).

\section{RESULTADOS E DISCUSSÃO}

Os quadrados médios das anàlises de variâncias, coeficientes de variação ambiental (CVe) e médias das cinco características encontram-se na Tabela 1. Percebe-se que existem diferenças estatísticas entre as progênies para todas as características, com excessão para comprimentro do fruto (CF). O CVe foi de $7,7 \%$ para diâmetro do fruto (DF) a $25,7 \%$ para número de frutos por planta (NF).

Na Tabela 2 pode-se observar que a contribuição da variância genotípica entre progênies $\left(o_{\mathrm{p}}^{2}\right)$ na variância fenotípica total $\left(\sigma_{F}^{2}\right)$ só se mostra baixa para $\mathrm{CF}$, enquanto que para as demais características esta contribuição ultrapassa os $40 \%$. A variação verificada dentro de progênies e os efeitos da interação do ambiente com este caráter, que não foram isolados, e estão 
Tabela 1. Quadros médios das análises de variãncias do ensinode avaliação de progênies de meios irmāos de maxixe (Cacumis anguria L.)

\begin{tabular}{lccccccc}
\hline $\begin{array}{c}\text { Causa } \\
\text { da } \\
\text { Variação }\end{array}$ & G. L. & CF & DF & ESP & PMF & NF' & PROD $^{2}$ \\
\hline Repartiçõe & 3 & - & - & - & - & - & - \\
Progênies & 18 & 0,28 ns. & $0,14^{*}$ & $0,62^{\star \star}$ & $30,57^{*}$ & $1,19^{* *}$ & $0,33^{\star \star}$ \\
Erro & 54 & 0,21 & 0,08 & 0,18 & 27,26 & 0,43 & 0,13 \\
\hline Media & & 5,31 & 3,59 & 4,64 & 30,15 & 2,55 & 2,11 \\
CVe \% & & 8,77 & 7,70 & 9,30 & 17,32 & 25,71 & 17,23 \\
\hline
\end{tabular}

1) Dados transformados para $\vee \neg x+1$

2) Dados transformados para $\log x$

n. s. : não significativo

* significativo a $5 \%$ de probabilidade pelo teste $\mathrm{F}$

** significativo a $1 \%$ de probabilidade pelo teste $\mathrm{F}$

Tabela 2. Estimativas dos componentes de variância em progênies de meios irmãos de maxixe (Cucumis anguria L.)

\begin{tabular}{|c|c|c|c|c|c|c|}
\hline \multirow{2}{*}{ Característica } & \multicolumn{6}{|c|}{ Estimativas dos componentes } \\
\hline & Unid. & Transf. & $o^{2} p$ & $o^{2} \mathrm{e}$ & $\sigma^{2} \mathrm{~A}$ & $o^{2} \mathrm{~F}$ \\
\hline CF & $\mathrm{cm}$ & - & 0.018 & 0.216 & 0.069 & 0.088 \\
\hline$D F$ & $\mathrm{~cm}$ & - & 0.016 & 0.077 & 0.069 & 0.088 \\
\hline ESP & $\mathrm{mm}$ & - & 0.108 & 0.186 & 0.433 & 0.155 \\
\hline PMF & g. & - & 9.599 & 27.266 & 38.398 & 16416 \\
\hline NF & num & $v \neg x+1$ & 0.189 & 0.431 & 0.756 & 0.296 \\
\hline PROD & $g / p$ & $\log x$ & 0.049 & 0.132 & 0.199 & 0.83 \\
\hline
\end{tabular}

$o^{2} p=$ variância genética entre progênies de meios irmãos (média)

$o^{2} \mathrm{e}=$ variância ambiental dentro de parcelas

$o^{2} A=$ variância genética aditiva

$o^{2} \mathrm{~F}=$ variância fenotípica total

contidos no quadrado médio do erro experimental entre outras causas, podem explicar este baixo valor (PATERNIANI, 1968).
A Tabela 3 evidencia as estimativas dos coeficientes de herdabilidade, ao nível de médias $\left(\mathrm{h}_{\mathrm{m}}^{2} \%\right)$, a média geral da população original e da selecionada $\left(\mathrm{X}_{\mathrm{O}} \mathrm{e}\right.$ 
Tabela 3. Estimativa de alguns parâmetros genéticos referentes aos caracteres de fruto e de produção em progênies de meios irmãos de maxixe (Cucumis anguria L.)

\begin{tabular}{lcrrrrrrr}
\hline \multirow{2}{*}{ Caracteristicas } & \multicolumn{9}{c}{ Média } & & & & \\
\cline { 3 - 5 } & Unid. & \multicolumn{1}{c}{ Xo } & Xs & $h^{2} \mathrm{~m} \%$ & CVg & b & Gs \% \\
\hline CFCM & $\mathrm{cm}$ & 5,31 & 5,41 & 24,20 & 7,39 & 0,84 & 1,89 \\
DF & $\mathrm{cm}$ & 3,60 & 3,73 & 45,54 & 3,52 & 0,45 & 3,67 \\
ESP & $\mathrm{mm}$ & 4,04 & 5,07 & 69,95 & 7,09 & 0,43 & 9,19 \\
PMF & g. & 30,15 & 33,82 & 58,47 & 2,74 & 0,15 & 3,67 \\
NF & un. & 5,52 & 8,53 & 63,70 & 17,03 & 0,67 & 20,94 \\
PROD & g/p. & 185,27 & 192,71 & 60,12 & 10,55 & 0,61 & 8,19 \\
\hline
\end{tabular}

Média: $X_{0}=$ média da pop. original e $\mathrm{Xs}=$ média da nova pop.;

$\mathrm{h}^{2} \mathrm{~m} \%=$ herdabilidade no sentido restrito ao nivel de média;

Cvg = coeficiente de variação genética;

Gs $K=\frac{o^{2} \mathrm{p}}{\mathrm{o}^{2} \mathrm{~F}} \quad$ onde, $\mathrm{K}=1,549$ e i. $\mathrm{s} .=20,0 \%$

$\mathrm{X}_{\mathrm{S}}$ ), o coeficiente de variação genético (CVg) e o quociente b ( $\mathrm{CVg} / \mathrm{CVe})$ bem como o ganho genético $\left(\mathrm{G}_{\mathrm{S}}\right)$, previsto com a seleção de $20 \%$ das progênies.

Os valores de herdabilidade variaram de $24,20 \%$ para $\mathrm{CF}$ a $69,95 \%$ para ESP. Esses mesmos parâmetros já haviam sido estimados, com outra amostra de 64 progênies de maxixe sem espículos, extraidas da mesma população original, cujos resultados para NF e PROD mostraram valores de herdabilidade superiores aos observados neste trabalho (PAIVA, 1984). As discrepâncias podem ser explicadas provavelmente pelo pequeno número de progênies que foram avaliadas. Porém, fica evidente que existe suficiente variabilidade genética para ser explorada com o melhoramento.

O quociente b serve, de acordo com VENKOVSKY (1978), como uma informação adicional e em progênies de meios irmãos, os valores próximos ou superiores a 1,0 indicam uma situação muito favorável para a seleção. Sob este aspecto, apenas três características (PROD, NF e CF) mostrarão ganhos efetivos com a seleção.

O ganho esperado com a seleção de $20 \%$ das melhores progênies pode provocar um acréscimo de 1,89\% para CF, $3,67 \%$ para DF, $4,38 \%$ para ESP, $3,67 \%$ para $\mathrm{PMF}, 20,94 \%$ para NF e $8,09 \%$ para PROD.

Com relação aos caracteres de fruto, tais como comprimento, diâmetro e espessura os valores mostram-se baixos e evidenciaram que neste, a seleção proporcionará pouco benefício. Portanto. aconselha-se que futuros programas de melhoramento em maxixe sejam iniciados a partir de uma população que já apresente média alta para esses 
caracteres. Então a seleção poderá ser dirigida para a obtenção de plantas mais prolíficas, ou seja, com maior número de frutos, caráter em que as possibilidades de ganhos efetivos é mais garantido. Esse mesmo procedimento também foi sugerido por SMITH et al. (1978) em pepino (Cucumis sativus $L$.) desde que, nesta espécie, o número de frutos está geneticamente e fenotípicamente correlacionado com a produção. A seleção para a prolificidade é uma forma indireta de aumentar a produção de frutos por planta.

\section{Bibliografia Citada}

KOCK, P. S.; COSTA, C. P. 199.1 Herança de caracteres de planta e fruto em maxixe.Horticultura brasileira, 9(2):73-77.

MIKI, K. 1986. Efeito heterótico e endogamia em maxixe (Cucumis anguria L). Monografia, Departamento de Ciências Agrárias. Fundação Universidade do Amazonas. Manaus,Amazonas. 39p.

PAIVA, W. O. 1984. Estimativas de parâmetros genéticos em maxixe (Cucumis anguria L.) Acta Amazonica. 14(1-2):39-47.
PATERNIANI, E. 1968. Avaliação do método de seleção entre e dentro de família de meios imrãos no melhoramento do milho. Tese de livre docência, Escola Superior de Agricultura "luiz de Queiróz", Universidade de Sāo Paulo. 92p.

PIMENTEL GOMES, F. Curso de Estatística Experimental. 1978. Piracicaba, São Paulo, Livraria NObel, $8^{\text {a }}$ ed. 430 p.

SMITH, O. S.; LOWER, R. L.; MOLL, R. H. 1978. Estimates of heritability and variance components of picking cucumber. J. Amer. Hort. Sci. 103(2): 222-225.

VENKOVSKY, R.; 1978. Genética Quantitativa. In. E.Paterniani, Melhoramento e Produção de milho no Brasil. Fundação Cargill Piracicaba, São Paulo, p. 122-195.

VENKOVSKY, R.; BARRIGA,P.92.Genética bionctrica Fitomelhoramento. Revista Brasileira de Genética. RibeirãoPreto,SãoPaulo.,496p.

YOKOYAMA, S. 1987. Genética e produção de sementes de maxixe (Cucunis anguria L.) relacionados com o seu melhorameno. Tese de doutorado, Escola Superior de Agricultura "Luiz de Queiróz", Universidade de São Paulo, Piracicaba, São Paulo. 115p. 